\title{
PEMBANGUNAN MASYARAKAT MISKIN DI PEDESAAN PERSPEKTIF FUNGSIONALISME STRUKTURAL
}

\author{
Nikodemus Niko, Yulasteriyani \\ Universitas Padjadjaran, Universitas Sriwijaya \\ Email:nikodemusniko@outlook.com, yulasteriyani@fisip.unsri.ac.id
}

Diterima: 09 Juli 2020 | Direvisi: 15 Agustus 2020 | Disetujui: 24 September 2020

\begin{abstract}
Indonesia as a developing country continues to make improvements in the program and policy of quality of life and human resources development. The new vision of Indonesia's president is 'SDM unggul Indonesia maju' and this vision also applied by government today shows that the government is serious about improving human resources quality. The sustainable development program is the benchmark for how seriousness of this country performs evaluation and improvement for a fair and prosperous welfare of society. The pattern of community-based development has been integrated and structured into a challenge in the policy model of sustainable program. This paper focuses on the development issue of rural communities with critical to the thought of functional structural theories. The approach used is qualitative study of the library by using scientific research of both articles, journals, as well as related agency data. This paper explains that the social structure that occurs in rural communities, gives an unsubstantial impact on the development of the poor. Then, the development that is still on the functional structural is the benchmark in overcoming the reality of poverty in the rural community today. Nevertheless, the development of functional structural perspectives is still difficult to be contributed to the significance of Community welfare development. It is concluded that community development programs are still loaded with importance and vulnerable to being politicized by the elite.
\end{abstract}

Keywords: community development, rural, empowerment, functional structural 


\begin{abstract}
Abstrak
Indonesia sebagai negara berkembang terus melakukan perbaikan dalam program dan kebijakan pembangunan kualitas hidup dan sumber daya manusia (SDM). Visi baru 'SDM unggul Indonesia maju' pemerintahan saat ini menunjukkan bahwa pemerintah serius dalam perbaikan kualitas SDM. Program pembangunan berkelanjutan menjadi tolok ukur bagaimana keseriusan negara melakukan evaluasi dan perbaikan demi tingkat kesejahteraan masyarakat yang adil dan makmur. Pola pembangunan masyarakat berbasis ekonomi telah terintegrasi dan terstruktur menjadi tantangan tersendiri dalam model kebijakan program berkelanjutan. Tulisan ini berfokus pada isu pembangunan masyarakat pedesaan dengan kritikal terhadap pemikiran teori struktural fungsional. Pendekatan yang digunakan adalah kualitatif studi pustaka dengan menggunakan penelitian-penelitian ilmiah baik artikel jurnal, serta data instansi terkait. Tulisan ini menjelaskan bahwa struktur sosial yang terjadi pada masyarakat pedesaan, memberi dampak yang tidak besar pada pembangunan masyarakat miskin. Kemudian, pembangunan yang masih berlandas pada struktural fungsional menjadi tolok ukur dalam mengatasi realitas kemiskinan masyarakat di pedesaan hari ini. Meski demikian, pembangunan berperspektif struktural fungsional masih sulit direstruktur terhadap signifikansi pembangunan kesejahteraan masyarakat. Sehingga disimpulkan bahwa program pembangunan masyarakat masih sarat dengan kepentingan dan rentan dipolitisir oleh golongan elit.
\end{abstract}

Kata Kunci: Pembangunan Masyarakat, Struktur Sosial, dan Struktural Fungsional.

\title{
Pendahuluan
}

Masyarakat pedesaan merupakan masyarakat yang mendiami wilayah tertentu yang disebut sebagai desa. Masyarakat desa selalu memiliki ciri tertentu yang unik dalam kehidupan bermasyarakat. Biasanya hal ini tampak dalam keseharian mereka. Pada tingkat tertentu permasalahan yang terjadi di desa sangat beragam, seperti misalnya masalah ekonomi, masalah kebudayaan, masalah sosial, dan masalah sumber daya manusia. Masalah ekonomi yang biasanya terjadi pada masyarakat desa umum di alami oleh masyarakat di berbagai wilayah pedesaan di Indonesia. Niko (2019) menyebutkan pada konteks masyarakat yang masih mempertahankan adat istiadat lokal di pedesaan, cenderung terisolasi dan hidup miskin. Oleh karena itu, pemberdayaan masyarakat pedesaan yang tepat sasaran menjadi hal yang selalu dinantikan setiap pergantian rezim presiden.

Aktivitas perekonomian masyarakat di wilayah pedesaan rata-rata bekerja di sektor pertanian, yang notabenenya keberhasilannya belum dapat dipastikan. Apalagi dari segi kepemilikan lahan banyak masyarakat desa yang tidak memiliki lahan pertanian, dalam artian ini mereka hanya menjadi buruh tani. Sedangkan petani yang 
bekerja di lahan milik pribadi pemanfaatan lahan yang mereka kelola dirasa belum terpadu untuk meningkatkan pendapatan ekonomi mereka. Sistem pertanian subsisten sudah mulai berubah ke pertanian komersial juga terus digalakkan untuk pembangunan masyarakat pedesaan. Artinya bahwa masyarakat yang berdaya dapat diartikan sebagai masyarakat yang mampu swasembada pangan. Santoso (2014) mengungkapkan fakta bahwa ancaman rawan pangan nasional yang kian parah pada rumah tangga miskin di pedesaan ternyata erat kaitannya dengan naiknya harga pangan.

Maxwell (1994) mengamati perubahan-perubahan yang terjadi tentang pendefinisan konteks ketahanan pangan menyebutkan setidaknya 3 perubahan penting yang terjadi yakni adanya perubahan dari tingkat global dan nasional ke tingkat rumah tangga (household) dan individu (individual), kemudian dari perspektif pangan sebagai kebutuhan dasar (food first perspective) berubah menjadi perspektif penghidupan (livelihood perspective) dan dari indikator-indikator yang objektif (objective indicators) ke presepsi yang subjektif (subjective perception).

Masalah kebudayaan yang terjadi di wilayah pedesaan, dengan berkembang pesat teknologi masa kini, mulai luntur budaya-budaya lokal. Banyak budaya asing yang masuk ke wilayah pedesaan tanpa adanya filterisasi atau penyaringan. Sehingga nilai-nilai budaya lokal mulai tergerus oleh perkembangan jaman. Perubahan sistem sosial budaya masyarakat pedesaan memiliki dampak positif dan negatif terhadap perkembangan dan pembangunan masyarakat pedesaan sehingga perlu akomodasi masyarakat untuk dapat memanfaatkan arus global-modern. Karena tidak semua nilai lokal harus dilestarikan serta tidak semua unsur modern-global buruk bagi masyarakat.

Masalah sumber daya manusia yang terjadi pada masyarakat pedesaan yaitu selalu bersentuhan langsung dengan masalah pendidikan di pedesaan. Sarana dan sarana pendidikan yang masih kurang memadai di wilayah pedesaan, berpengaruh langsung terhadap kualitas sumber dayam manusia yang ada di desa. Bahkan pada tingkat kampung-kampung tertentu, masih banyak masyarakat yang tidak mengenyam pendidikan, walau hanya di bangku sekolah dasar. Permasalahan sarana dan prasarana, juga termasuk didalamnya masalah jalan, masalah air bersih, bahkan listrik.

Atas permasalahan sosial budaya masyarakat pedesaan, Indonesia telah melakukan upaya pembangunan dan pemberdayaan baik via pemerintah maupun swasta. Usaha-usaha pembangunan dan pengentasan kemiskinan ini mengalami 
berbagai hambatan dan tantangan sehingga pihak yang bertanggungjawab perlu melakukan evaluasi dan perbaikan. Parsialitas pembangunan sosial budaya di Indonesia turut mempengaruhi kesuksesan program kebijakan pembangunan masyarakat. Meski pada kenyataan hari ini perempuan miskin di pedesaan terus berjuang atas kesulitan ekonomi, bahkan memaksa remaja perempuan dari keluarga miskin untuk bekerja sebagai pekerja seks komersial, untuk keluar dari jerat miskin (Jurnal Perempuan, 2005).

Pembangunan ekonomi menjadi momok menakutkan jika tidak diiringi pembangunan kualitas manusia yang berkelanjutan. Hilangnya identitas pembangunan yang notabenenya untuk kesejahteraan rakyat (Khomsan, 2012). Pilihan pendekatan pembangunan yang berorientasi pada pertumbuhan ekonomi bukan saja telah mengakibatkan berbagai bentuk ketimpangan sosial tetapi juga menimbulkan berbagai persoalan lain seperti timbulnya akumulasi nilai-nilai hedonistik, ketidakpedulian sosial, erosi ikatan kekeluargaan dan kekerabatan. (Dwijayanto, 2018).

Kemudian, lebih dari itu pendekatan pembangunan tersebut telah menyebabkan ketergantungan masyarakat pada birokrasi-birokrasi sentralistik yang memiliki daya absorsi sumber daya yang sangat besar. Namun, tidak memiliki kepekaan terhadap kebutuhan-kebutuhan lokal, dan secara sistematis telah mematikan inisiatif masyarakat lokal untuk memecahkan masalah-masalah yang mereka hadapi (Korten, 1987). Tulisan ini menjadi jalan tengan untuk mendiskusikan sebab-sebab pembangunan masyarakat pedesaan yang cenderung struktural dan formalitas. Kritik atas struktural fungsional yang merupakan konsep lama pembangunan di negara-negara sedang berkembang, termasuk Indonesia.

\section{Kerangka Gagasan Fungsional Struktural (Talcott Parson)}

Struktural fungsional merupakan sebuah sudut pandang yang berupaya menafsirkan masyarakat sebagai sebuah struktur dengan bagian-bagian yang saling berhubungan. Dalam hal ini Fungsionalisme menafsirkan masyarakat secara keseluruhan dalam hal fungsi dan elemen-elemen konstituennya; terutama norma, adat, tradisi, dan institusi. Sebuah analogi umum yang di populerkan oleh Herbert Spencer menampilkan bagian-bagian masyarakat ini sebagai "organ" yang bekerja demi berfungsinya seluruh "badan" secara wajar. Dalam arti paling mendasar, istilah ini 
menekankan "upaya untuk menghubungkan, sebisa mungkin, dengan setiap fitur, adat, atau praktik, dampaknya terhadap kebefungsian suatu sistem yang stabil dan kohesif.

Teori fungsional struktural merupakan sebuah pondasi teori yang paling besar pengarruhnya dalam ilmu sosial pada abad sekarang. Tokoh-tokoh yang pertama kali mencetus teori ini yaitu Auguste Comte, Emile Durkheim dan Herbert Spencer. Pemikiran struktural fungsional sangat dipengaruhi oleh pemikiran biologis yaitu menganggap masyarakat sebagai organisme biologis yaitu terdiri dari organ-organ yang saling ketergantungan. Ketergantungan tersebut merupakan hasil atau konsekuensi agar organisme tersebut agar tetap bertahan hidup. Teori fungsional mengatakan bahwa masyarakat merupakan suatu sistem sosial yang terdiri atas bagian-bagian atau elemen yang saling berkaitan dan saling menyatu dalam keseimbangan (Ritzer, 1985). Teori struktural fungsional ini awalnya berangkat dari pemikiran Emile Durkheim, dimana pemikiran Durkheim ini dipengaruhi oleh Auguste Comte dan Herbert Spencer dengan membandingkan dan mencari kesamaan antara masyarakat organisme, sehingga pada akhirnya berkembang menjadi apa yang disebut requisite functionalism, dimana ini menjadi panduan bagi analisis substantif Spencer dan penggerak analisis fungsional.

Sebagaimana disebutkan dalam teori fungsional bahwa perubahan yang terjadi pada satu bagian akan membawa perubahan terhadap bagian yang lain. Asumsi dasarnya adalah bahwa setiap struktur dalam sistem sosial, fungsional terhadap yang lain (Ritzer, 1985). Studi Durkheim terhadap terminology organismik mengungkapkan bahwa masyarakat adalah sebuah kesatuan dimana didalamnya terdapat bagian-bagian dari sistem yang mempunyai funsgi masing-masing sehingga seimbang. Bagian-bagian tersebut saling interpendensi satu sama lain dan fungsional, sehingga jika ada yang tidak berfungsi maka akan merusak keseimbangan sistem. Pemikiran inilah yang menjadi sumbangsih Durkheim terhadap pemikiran Talcott Parsons.

Teori Struktural Fungsional menjadi teori yang dominan digunakan dalam perspektif sosiologi. Teori Fungsional menjadi karya Talcott Parsons dan Robert K. Merton dibawah pengaruh tokoh-tokoh pendahulunya. Menurut kacamata teori fungsional masyarakat senantiasa berada dalam keadaan berubah secara berangsungangsur dengan tetap memelihara keseimbangan (Ritzer, 1985). Sebagai ahli teori yang paling mencolok di jamannya, Talcott Parsons menimbulkan kontroversi atau pendekatan fungsionalisme yang ia gulirkan. Dalam karyanya Parsons membangun teori 
sosiologi nya melalui "analytical realism", maksudnya adalah teori sosiologi harus menggunakan konsep-konsep tertentu yang memadai dalam melingkupi dunia luar. Konsep ini tidak bertanggungjawab pada fenomena konkrit, tapi kepada elemen-elemen didalamnya yang secara analitis dapat dipisahkan dari elemen-elemen lainnya. Parsons kemudian menawarkan suatu skema penting dalam sistem tindakan, sebagai berikut:

Gambar 1.1. Skema AGIL Talcott Parsons

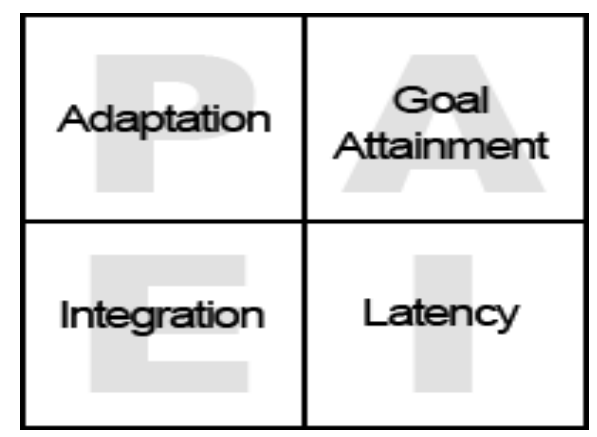

Sumber: Ritzer \& Goodmaan, 2004

Sistem tindakan diperkenalkan oleh Parsons dengan skema AGIL-nya yang terkenal. Talcott Parsons (dalam Ritzer \& Goodmaan, 2004) meyakini bahwa ada empat fungsi penting untuk semua sistem tindakan, yaitu:

1. Adaptation (adaptasi): sebuah sistem harus menanggulangi situasi eksternal yang gawat. Sistem harus menyesuaikan diri dengan lingkungan dan menyesuaikan lingkungan itu dengan kebutuhannya.

2. Goal Attainment (pencapaian tujuan): sebuah sistem harus mendefinisikan dan mencapai tujuan utamanya.

3. Integration (integrasi): sebuah sistem harus mengatur antarhubungan bagian-bagian yang menjadi komponennya. Sistem juga harus mengelola antarhubungan ketiga fungsi penting lainya (adaptation, goal Attainment, dan latency).

4. Latency (latensi atau pemeliharaan pola): sebuah sistem harus memperlengkapi, memelihara dan memperbaiki, baik motivasi individual maupun pola-pola kultural yang menciptakan dan menopang motivasi.

Sistem tindakan hanya akan bertahan jika memenuhi empat kriteria diatas. Dalam karya Parsons berikutnya yaitu "The Social System", Parsons melihat aktor sebagai orientasi pada situasi dalam istilah motivasi dan nilai-nilai. Kemudian ia memperkenalkan macam-macam motivasi antara lain kognitif, chetectic, dan evaluatif. Selain itu terdapat juga nilai-nilai yang bertanggungjawab terhadap sistem sosial ini 
yaitu nilai kognisi, apresiasi dan moral, dalam hal ini Parsons menyebutnya sebagai modes of orientation.

Menurut Parsons (Maliki, 2003), terdapat fungsi-fungsi atau kebutuhankebutuhan tertentu yang dipenuhi oleh setiap sistem yang hidup demi kelestariannya. Dalam hal ini, ada dua kebutuhan penting untuk dipenuhi. Pertama, yang berhubungan dengan kebutuhan sistem internal atau kebutuhan sistem ketika berhubungan dengan lingkungannya. Kedua, yang berhubungan dengan pencapaian sasaran atau tujuan serta sarana yang perlu untuk mencapai tujuan itu. Dalam mencapai tujuan dipengaruhi oleh nilai-nilai dan norma-norma, serta situasi dan kondisi yang melingkupi.

Akhir dari analisis ini adalah visi metafisis yang besar oleh dunia yang telah menimpa eksistensi manusia. Analisis Parsons sendiri merepresentasikan suatu usaha untuk mengkategorisasikan dunia ke dalam sistem, subsistem, persyaratan-persyaratan system, generalisasi media dan pertukaran menggunakan media tersebut. Analisis ini pada akhirnya lebih filosofis daripada sosiologis, yakni pada lingkup visi meta teori.

Pada tulisan ini menggunakan jenis metode penelitian kualitatif deskriptif dengan eksplorasi data sekunder. Data sekunder dalam penelitian ini didapatkan melalui penelusuran tulisan-tulisan ilmiah seperti jurnal ilmiah dan buku yang terkait dengan tema. Analisis data dilakukan pada saat yang bersamaan dengan penulisan laporan penelitian ini, sehingga verifikasi data juga dilakukan pada saat yang bersamaan. Verifikasi data dilakukan berdasarkan sumber data, seperti jurnal ilmiah. Sehingga metode keabsahan data adalah triangulasi sumber data.

\section{Pembangunan Masyarakat Pedesaan}

Pembangunan pedesaan penting dilakukan untuk menjadikan desa sebagai sumber kekuatan lokal. Terlebih masyarakat Indonesia merupakan masyarakat agraris, dalam arti lain bahwa sebagian besar masyarakat Indonesia bertani. Pembangunan pedesaan yang dimaksud disini berbeda dengan pembangunan yang pada umumnya berfokus pada pembangunan jembatan, jalan, atau teknologi pertanian. Namun lebih kepada pembangunan manusia-nya, dengan jalan pendidikan.

Pada masyarakat pedesaan, organisasi tingkat desa hingga dusun berjalan dengan fungsional, dengan melibatkan masyarakat adat. Masyarakat ini yang kemudian dijadikan subjek dalam pembangunan. Hudayana (2017) berpendapat bahwa cara kerja 
untuk terjun langsung ke masyarakat dalam rangka advokasi program-program yaitu melalui program aksi untuk melakukan perubahan.

Proses-proses adaptasi ekonomi dan ekologis yang dibentuk oleh petani (arasindividual), rumah tangga (aras kelompok) serta komunitas lokal (aras sistem sosial) sebagai upaya menyelaraskan eksistensi mereka terhadap arus perubahan sosial, menghasilkan sejumlah gambaran dinamika sistem penghidupan dan nafkah pedesaan (Dharmawan, 2007). Artinya bahwa keberdayaan masyarakat sudah terbangun pada relasi individual hingga sistem sosial. Hal ini menjadi modal sosial untuk pemberdayaan lokal. Pembangunan dan pengembangan kualitas sumber daya manusia di Indonesia telah memiliki struktur dan pola yang sudah pakam. Parsialitas pembangunan masyarakat cenderung konsen di bidang ekonomi sebaliknya berpaling pada pembangunan menyeluruh (sosial budaya dan politik) (Wahyu, 2014). Sehingga perlu perubahan sosial pembangunan kualitas sumber daya manusia. (Wahyudin, 2012) menjelaskan bahwa pembangunan masyarakat desa mencakup berbagai pendekatan dan kegiatan yang bertujuan untuk meningkatkan kesejahteraan dan mata pencaharian penduduk yang tinggal di wilayah pedesaan.

Sebagai cabang dari pengembangan masyarakat, perlu menggunakan pendekatan seperti pendekatan sosial kemasyarakatan. Perlunya upaya inovatif untuk mengakselerasi pengentasan kemiskinan selain yang sudah dilakukan selama ini. Karena sumber utama kemiskinan adalah rendahnya kualitas sumberdaya manusia (SDM) yang disebabkan oleh minimnya tingkat pendidikan yang berkualitas dan sikap mental pada sebagian besar masyarakat Indonesia.

\section{Pembangunan Masyarakat Miskin di Pedesaan Perspektif Fungsionalisme Struktural}

Tujuan pelaksanaan pembangunan, diantaranya adalah meningkatkan ketersediaan serta memperluas distribusi kebutuhan dasar rakyat banyak. Meningkatkan taraf hidup antara lain pendapatan meningkat, kesempatan kerja yang cukup, pendidikan yang lebih baik, perhatian yang lebih besar kepada nilai-nilai kebudayaan dan kemanusiaan (dalam arti kesejahteraan sosial, jasmani, dan rohani). Serta untuk memperluas pilihan-pilihan sosial ekonomi dari perseorangan dan bangsa dengan memberikan kebebasan dari ketergantungan (Todaro, 2004). 
Pemerintah telah melakukan upaya pembangunan kualitas sumber daya manusia berbasis rumah tangga agar menjadi pembangunan manusia yang berkelanjutan. Program Keluarga Harapan (PKH) merupakan program bantuan yang baik dalam memberikan kontribusi sebagai upaya menurunkan angka kemiskinan. Tujuan yang terdapat dalam pelaksanaan program ini sangat jelas dan detail dalam Pedoman Umum Pelaksanaan Program Keluarga Harapan (PKH) diantaranya yaitu meningkatkan kondisi sosial ekonomi RTSM, meningkatkan taraf pendidikan anak-anak RTSM, meningkatkan status kesehatan dan gizi ibu hamil, ibu nifas, dan anak di bawah 6 tahun di RTSM, dan meningkatkan akses dan kualitas pelayanan pendidikan dan kesehatan, khususnya bagi RTSM (Anonim, 2008).

Berkaitan dengan pembangunan manusia ini Sen (1992) mengemukakan konsep-konsep tentang pembangunan yang disebut dengan teori kapabilitas (Capability Theory) yang di dalamnya mengandung visi dan unsur-unsur khusus sebagai basic dari pembangunan. Masalah pembangunan sejatinya adalah tentang pengelolaan keberagaman dan pencapaian keadilan. Oleh karena itu pembangunan harus mengatasi kedua masalah tersebut dengan dua hal, yaitu membuka pintu-pintu kebebasan (means of freedom) selebar-lebarnya dan memberikan pendapatan selayak-layaknya bagi setiap potensi dan tenaga yang bekerja untuk berkembang (Sen, 1992).

Isu sentral masalah pembangunan yang masih menghantui Bangsa Indonesia saat ini adalah masalah pengangguran dan masalah kemiskinan. Kedua permasalahan besar ini terjadi pada masyarakat pedesaan pada umumnya. Secara umum, subjektivitas miskin dari perspektif lembaga/akademisi dan teoritisi di Indonesia masih menggunakan cara pandang bahwa miskin berarti ketidakmampuan dalam pemenuhan kebutuhan dasar ekonomi (Yulasteriyani, Randi, \& Hasbi, 2020).

Sejak pemerintahan Orde Baru, pemerintah meluncurkan berbagai program pengentasan kemiskinan dan pemberdayaan masyarakat yang dijalankan oleh berbagai kementerian dan lembaga. Salah satu yang terkenal adalah Program Inpres Desa Tertinggal (IDT) yang ditujukan untuk meningkatkan kualitas kesejahteraan masyarakat miskin melalui pengembangan sumberdaya manusia, modal, dan usaha produktif serta pengembangan kelembagaan. Mulai tahun 2006 pemerintah telah memiliki konsep penanggulangan kemiskinan secara terpadu dengan basis pemberdayaan masyarakat. Program yang diresmikan oleh Presiden Susilo Bambang Yudhoyono di Palu pada 
tanggal 1 Mei 2007 ini, bernama Program Nasional Pemberdayaan Masyarakat (PNPM) Mandiri dengan tujuan meningkatkan keberdayaan dan kemandirian masyarakat (Hadi, 2011). Program ini merupakan salah satu program utama pemerintah dalam menanggulangi kemiskinan dan perluasan kesempatan kerja, selain program-program lain yang telah ada, seperti Raskin, Askeskin, pengembangan usaha mikro, kecil dan menengah, pengembangan bahan bakar nabati dan energi alternatif, peningkatan ketahanan pangan, sertifikasi tanah bagi masyarakat miskin

Program lain, yang merupakan program struktural yang sifatnya fungsional adalah Program Pengembangan Kecamatan (PPK) yang merupakan salah satu upaya Pemerintah Indonesia yang bertujuan untuk meningkatkan kesejahteraan masyarakat perdesaan, memperkuat institusi lokal, dan meningkatkan kinerja pemerintah daerah. PPK telah dimulai sejak Indonesia mengalami krisis multidimensi dan perubahan politik pada 1998. PPK dirancang sebagai bagian dari program pembangunan untuk mempercepat penanggulangan kemiskinan khususnya di wilayah perdesaan. Program diimplementasikan melalui pengelolaan di tingkat kecamatan dalam bentuk pemberian dana bergulir untuk usaha ekonomi produktif dan penyediaan prasarana dan sarana yang menunjang kegiatan ekonomi, yang kesemuanya itu diarahkan sebagai upaya peningkatan kemampuan masyarakat (capacity building investment).

Lebih lanjut, program pengentasan kemiskinan pedesaan saat ini yang ada bertumpu pada implementasi pemberian dana segar kepada masyarakat miskin, yang sebenarnya konsep ini sama saja dengan program-program Bantuan Langsung Tunai di tahun-tahun sebelumnya. Implementasi kebijakan program pemberdayaan semestinya dilaksanakan dengan menggunakan mekanisme pelaksanaan yang bertumpu pada peran aktif masyarakat yang merupakan langkah nyata pemberdayaan masyarakat itu sendiri (Proefschrift, 1974; Khan \& Khandaker, 2016; Tika, Hanafi, \& Riyanto, 2017). Artinya bahwa partisipasi aktif kelompok sasaran menjadi sangat penting dalam melihat keberhasilan atau kegagalan program/implementasi kebijakan pemberdayaan. 


\section{Kesimpulan}

Konsep dan pendekatan program pembangunan khususnya pemberdayaan masyarakat sebagai bagian dari upaya pemerintah dalam menanggulangi kemiskinan masih berorientasi pada struktural fungsional. Secara konseptual kesemuanya sudah mengedepankan partisipasi masyarakat dan mengutamakan pemberdayaan dalam setiap langkah kegiatannya. Namun demikian, dalam implementasinya nilai-nilai partisipasi dan pemberdayaan masyarakat ini masih menjadi nomor dua dibandingkan dengan pencapaian target program dan proyek. Hal ini bermakna bahwa angka kuantifikasi tidak berbanding sama dengan kualitas capaian program pembangunan masyarakat di pedesaan.

Program pembangunan yang selama ini berlangsung di masyarakat hanya mementingkan pihak-pihak tertentu, tanpa mengutamakan masyarakat yang menjadi subjek program. Sehingga program-program yang bersifat struktural fungsional, yang basis kebijakannya dari atas, dalam artian terdapat kepentingan dalam program-program pembangunan masyarakat. Tidak heran jika masih terdapat banyak masyarakat pedesaan yang masih hidup di bawah garis kemiskinan. Penulis menyarankan bahwa program pembangunan masyarakat di pedesaan perlu evaluasi dan juga pengawasan berkala oleh pembuat kebijakan. Sehingga implikasinya secara kualitas, pembangunan masyarakat di wilayah desa masih biasa-biasa saja. Utamanya yang dapat dirasakan adalah kulaitas pembangunan sumber daya manusianya.

\section{Referensi}

Anonim. (2005). Perempuan dalam Strategi Penanggulangan Kemiskinan. Jurnal Perempuan. Ed. 42, 95-105.

. (2008). Pedoman Umum Pelaksanaan Program Keluarga Harapan (PKH). Jakarta: Kementerian Sosial RI.

Dharmawan, A. H. Sistem Penghidupan dan Nafkah Pedesaan: Pandangan Sosiologi Nafkah (Livehood Sociology) Mazhab Barat dan Mazhab Bogor. Jurnal Sodality. Vol. 1, 2007, Hal. 169-192.

Dwijayanto, A. (2018). Pemberdayaan Komunitas Muslim Perbukitan Melalui Program

Sosial Bank Indonesia di Kaur Bengkulu. Muharrik: Jurnal Dakwah dan Sosial, 1 (02), 155-167. 
Pembangunan Masyarakat Miskin...

Hadi, A. P. (2011). Tinjauan Terhadap Berbagai Program Pemberdayaan Masyarakat di Indonesia. Yayasan Agribisnis/Pusat Pengembangan Masyarakat Agrikarya. (Tidak diterbitkan).

Hudayana, B. (2017). Pemberdayaan Masyarakat: Bunga Rampai Antropologi Terapan. Yogyakarta: Pustaka Pelajar.

Khan, A. R., \& Khandaker, S. (2016). A Critical Insight into Policy Implementation and Implementation Performance. Public Policy and Administration. 15(4): 538-548.

Khomsan, A. (2012). Ekologi Masalah Gizi, Pangan dan Kemiskinan. Bandung: Alfabeta.

Korten, D. C. (1987). Community Management. Connectitut: Kumarian Press, Westaharford.

Maxwell. S. (1994). Food Security: a post-modern Perspective. Working paper 9 Institute of Development Studies University of Sussex, England.

Niko, N. (2019). Kemiskinan Perempuan Dayak Benawan di Kalimantan Barat sebagai Bentuk Kolonialisme Baru. Jurnal Pemikiran Sosiologi. 6(1): 58-76. Doi: https://doi.org/10.22146/jps.v6i1.47467

Proefschrift. (1974). Understanding How Actors Influence Policy Implementation. Universiteit Twente.

Ritzer, G. (2012). Teori Sosiologi Modern (terj. Alimandan). Jakarta: Kencana Prana Media Group. . (2014). Sosiologi Ilmu Berparadigma Ganda (terj. Ali Ramdani). Jakarta: Rajawasli Press.

Santoso, I. (2014). Pengembangan Masyarakat Berbasis Sumber Daya Lokal. Yogyakarta: Pustaka Pelajar.

Sen, A. (1992). Inequality Reexamined. New York: Sussel Sage Foundation.

Tika, F. Y. A., Hanafi, I. \& Riyanto. (2017). Implementasi Kebijakan Pemberdayaan Masyarakat (Studi pada Pelaksanaan Program Nasional Pemberdayaan Masyarakat (PNPM) Mandiri Perkotaan di Kecamatan Batu Kota Batu). Jurnal Administrasi Publik (JAP). 1(2): 188-196.

Todaro, M. P. (2004). Pembangunan Ekonomi Dunia ke-3 (Jilid 1, Edisi 8). Jakarta: Erlangga. 
Wahyudin, U. (2012). Pelatihan Kewirausahaan Berbasis Ekokultural untuk Pemberdayaan Masyarakat Miskin Pedesaan. Jurnal Mimbar. 28(1): 55-64.

Wahyu, D. K. (2014). Kamus Sosiologi. Surabaya: Victory Inti Cipta.

Yulasteriyani, Y., Randi, R., \& Hasbi, M. (2020). Kemiskinan Masyarakat di Indonesia: Perspektif Sosiologi Islam dan Fenomenologi Barat. Intizar, 25(2), 77-86. Doi: https://doi.org/https://doi.org/10.19109/intizar.v25i2.4463 